\title{
Exceptional Localization of a Prolactinoma as Part of Familial Isolated Pituitary Adenomas
}

\author{
Hind Asbar*, Maryame Benlafqih, Sara Askaoui, Sana Rafi, Ghizlane El Mghari, Nawal El Ansari \\ Department of Endocrinology, Diabetes, Metabolic Diseases and Nutrition, Mohammed VI University Hospital, Marrakech, \\ Morocco \\ Email: ^hind.asbar@gmail.com
}

How to cite this paper: Asbar, $\mathrm{H}$., Benlafqih, M., Askaoui, S., Rafi, S., El Mghari, G. and El Ansari, N. (2021) Exceptional Localization of a Prolactinoma as Part of Familial Isolated Pituitary Adenomas. Open Access Library Journal, 8: e7229.

https://doi.org/10.4236/oalib.1107229

Received: February 7, 2021

Accepted: March 15, 2021

Published: March 18, 2021

Copyright (c) 2021 by author(s) and Open Access Library Inc.

This work is licensed under the Creative Commons Attribution International License (CC BY 4.0).

http://creativecommons.org/licenses/by/4.0/

\section{Open Access}

\begin{abstract}
The syndrome of familial isolated pituitary adenomas (FIPA) or predisposition to pituitary adenomas (PAP) is characterized by the presence within the same family of at least two isolated pituitary adenomas without any other type of associated endocrine tumor. These pituitary tumors may present as homogenous with the same tumor phenotype or heterogeneous with different patterns of pituitary tumor phenotypes (GH, Prolactine, ACTH secretion or non-functioning pituitary adenomas) within the same kindred. Patients with FIPA are significantly younger at diagnosis and have significantly larger pituitary adenomas than matched sporadic pituitary adenoma counterparts. We report the case of a prolactinoma attached to the pituitary stalk as part of FIPA, revealed by erectile dysfunction.
\end{abstract}

\section{Subject Areas}

Diabetes \& Endocrinology

\section{Keywords}

Familial Isolated Pituitary Adenomas, Prolactinoma, Pituitary Stalk

\section{Introduction}

Pituitary adenomas are frequent intracranial tumors occurring particularly in young patients. Familial isolated pituitary adenomas (FIPA) include the usual occurrence of isolated pituitary adenomas outside the genetic syndromes, such as multiple endocrine neoplasia type 1 and Carney complex. It is secondary in $20 \%$ to the mutation of the AIP gene (Aryl hydrocarbon receptor-Interacting Protein), the latter is an element of poor prognosis [1].

Prolactinoma is the most common tumor in this setting. We report a case of 
prolactinoma of atypical localization in the setting of FIPA, revealed by primary infertility.

\section{Case Report}

A 40-year-old male, married for 10 years, consulted for primary infertility. The anamnesis found history of permanent erectile dysfunction since the age of 19 with loss of libido that was put on testosterone enanthate. In the family history, the presence of primary infertility treated by in vitro fertilization (IVF) was noted in 3 paternal cousins, two of whom were on dopaminergic agonists for documented prolactinomas.

The clinical examination of the patient showed testicles in place measuring on the right $12 \mathrm{ml}$ and on the left $16 \mathrm{ml}$ with a normal penis size and normal pubic hair. The biological assessment revealed a hyperprolactinemia at $289 \mathrm{ng} / \mathrm{ml}$ with hypogonadotropic hypogonadism while the rest of serum pituitary hormone levels (thyroid stimulating hormone [TSH], prolactin, adrenocorticotropic hormone $[\mathrm{ACTH}]$ and growth hormone $[\mathrm{GH}]$ ), as well as thyroid hormones, cortisol, insulin-like growth factor [IGF I], parathyroid hormone [PTH] were in the normal range for age and sex.

Pituitary MRI revealed the presence of a $27 \times 21 \times 14 \mathrm{~mm}$ mass suspended from the pituitary stalk (Figure 1) with a visual field within normal. The patient was put on cabergoline $2 \mathrm{mg}$ per week with poor compliance. After a 2-year follow-up, prolactin levels remained at $133 \mathrm{ng} / \mathrm{ml}$ with only modest changes in tumor size. So in view of fertility desire, the patient underwent tumor resection by transsphenoidal surgery. Immunohistochemistry (Figure 2) has confirmed staining of the tumor for prolactin, and negative staining for GH, FSH, LH, TSH, and ACTH. Ki 67 labeling index was inferior to 3\%. Genetic study was not feasible at our level.

The evolution was favorable with decrease in dopamine levels reaching 50 $\mathrm{ng} / \mathrm{ml}$. The last MRI control showed a pituitary adenoma of $8.7 \times 6 \times 5 \mathrm{~mm}$. Three IVFs were performed with failure, the 4 th was successful (wife was pregnant and gave birth to a healthy boy).

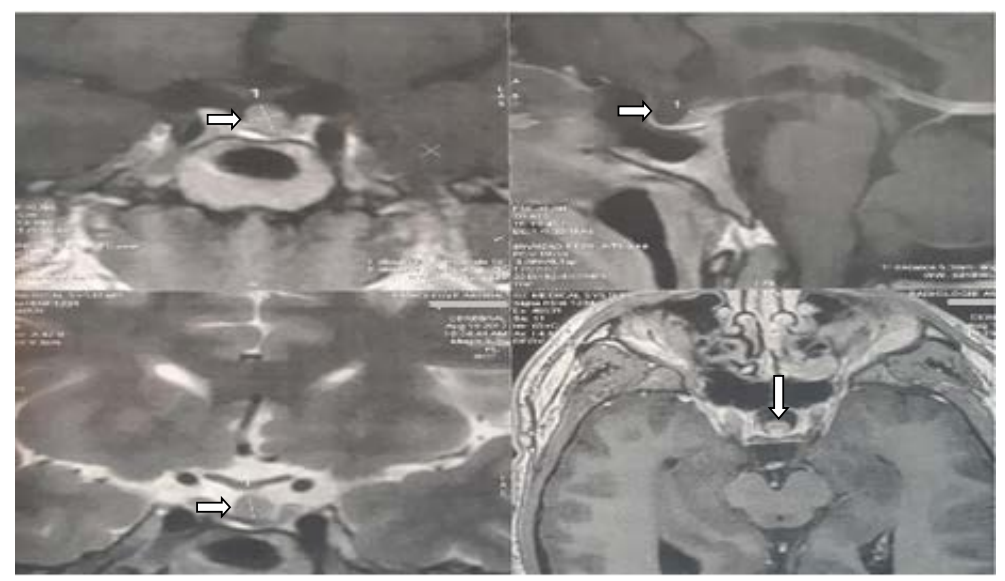

Figure 1. Mass attached to the pituitary stalk. 


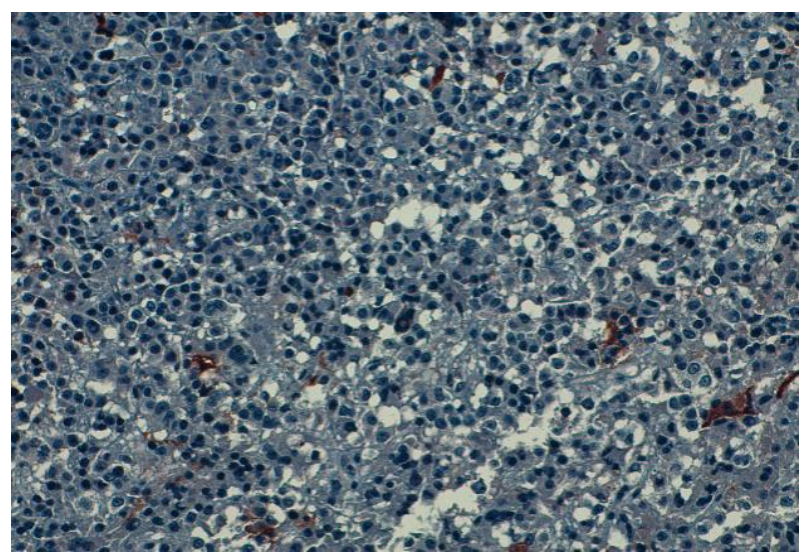

Figure 2. Photomicrograph (Hematoxylin-eosin, original magnification $\times 200$ ) showing positive immunostaining for anti-prolactin antibodies.

\section{Discussion}

Familial isolated pituitary adenomas (FIPA) are an inherited condition, quite rare, accounting for approximately two percent of pituitary adenomas [2]. It is characterized by development of a pituitary adenoma in two or more related members of the same kindred in the absence of other syndromic conditions like multiple endocrine neoplasia type 1 (MEN1) and Carney complex (CNC).

Tumors that form in the pituitary gland can release excess levels of one or more hormones. More than 200 families with FIPA have been described in the medical literature [1]. The frequency of different types of tumors in FIPA is: prolactinoma (37.5\%), somatotropinoma (35.0\%), non functional pituitary adenomas (14.5\%), somatolactotropinomas (6.4\%), Cushing disease (2.9\%), gonadotropinomas $(2.0 \%)$, plurihormonal tumors (1.2\%), and thyrotropinomas (0.5\%) [3] [4] [5]. Most FIPA cases concern two to three closely related kindreds although samples are relatively small due to limited familial anamnesis in many reported families.

Since the low prevalence of sporadic prolactinomas in the same family with no clinical or biological evidence of MEN1 or CNC, we considered that our patient presented a homogeneous FIPA type (prolactinoma) with two other family members. Response to medical treatment in prolactinomas as part of FIPA is variable. In our patient, response to dopaminergic agonists was modest as patient's desire of kids was not fulfilled after two years of treatment. A transsphenoidal surgery was then performed allowing an important regression of tumor size and drop of prolactin levels. Patient's wife had a baby within one year of surgery.

About 20\% of FIPA have mutations in the aryl hydrocarbon receptor interacting protein gene (AIP) usually associated with a worse outcome. They account for a minority of FIPA and are more found in families with homogeneous acromegaly, or heterogeneous phenotypes with acromegaly and prolactinoma [6] [7]. The molecular study of the AIP is necessary in the presence of pituitary adenomas, since it is associated with poor outcome. 


\section{Conclusions}

Familial pituitary adenomas account for approximately 5\% of pituitary adenomas and their clinical and genetic characterization has recently been enriched by the description of the new FIPA (Familial Isolated Pituitary Adenomas). This entity must be searched from anamnesis in front of any pituitary tumor and search by PCR (mutations of the AIP gene) given its prognostic interest.

Informed consent was obtained from the patient to report this case.

\section{Conflicts of Interest}

The authors declare no conflicts of interest regarding the publication of this paper.

\section{References}

[1] Beckers, A., Aaltonen, L.A., Daly, A.F. and Karhu, A. (2013) Familial Isolated Pituitary Adenomas (FIPA) and the Pituitary Adenoma Predisposition due to Mutations in the Aryl Hydrocarbon Receptor Interacting Protein (AIP) Gene. Endocrine Reviews, 34, 239-277. https://doi.org/10.1210/er.2012-1013

[2] Tichomirowa, M.A., Daly, A.F. and Beckers, A. (2009) Familial Pituitary Adenomas. Journal of Internal Medicine, 266, 5-18. https://doi.org/10.1111/j.1365-2796.2009.02109.x

[3] Daly, A.F., Jaffrain-Rea, M.L., Ciccarelli, A., Valdes-Socin, H., Rohmer, V., Tamburrano, G., et al. (2006) Clinical Characterization of Familial Isolated Pituitary Adenomas. The Journal of Clinical Endocrinology \& Metabolism, 91, 3316-3323. https://doi.org/10.1210/jc.2005-2671

[4] Daly, A.F., Petrossians, P. and Beckers, A. (2005) An Overview of the Epidemiology and Genetics of Acromegaly. Journal of Endocrinological Investigation, 28, 67-69.

[5] Beckers, A. and Daly, A.F. (2007) The Clinical, Pathological, and Genetic Features of Familial Isolated Pituitary Adenomas. European Journal of Endocrinology, 157, 371-382. https://doi.org/10.1530/EJE-07-0348

[6] Vierimaa, O., Georgitsi, M., Lehtonen, R., Vahteristo, P., Kokko, A., Raitila, A., et al. (2006) Pituitary Adenoma Predisposition Caused by Germline Mutations in the AIP Gene. Science, 312, 1228-1230. https://doi.org/10.1126/science.1126100

[7] Daly, A.F. and Beckers, A. (2015) Familial Isolated Pituitary Adenomas (FIPA) and Mutations in the Aryl Hydrocarbon Receptor Interacting Protein (AIP) Gene. Endocrinology and Metabolism Clinics, 44, 19-25. https://doi.org/10.1016/j.ecl.2014.10.002 